\title{
Models of Internet behavior of humanitarian orientation students, depending on gender
}

\author{
Irina Abakumova ${ }^{1}$, Galina Zvezdina ${ }^{1}{ }^{*}$, Anastasia Grishina ${ }^{1}$ and Elena Dyakova ${ }^{2}$ \\ ${ }^{1}$ Don State Technical University, Rostov-on-Don, Russia \\ ${ }^{2}$ Rostov State Transport University, Rostov-on-Don, Russia
}

\begin{abstract}
The article presents the results of an empirical study on models of Internet behavior of humanitarian students, taking into account their gender characteristics. The relevance of this study is determined by the active inclusion of modern students in the Internet space. The lack of studies on the problem of Internet behavior in the student community led to the need for empirical research. As an empirical object of research, we choose humanities faculties students of universities in Rostov-on-Don and the Rostov region in the amount of 60 people, including 28 young men and 32 young women. The psychological profiles of students' Internet behavior were studied, differences in the used models of Internet behavior in male and female samples were revealed. The features of Internet behavior are shown, indicating the fact that the student environment is dominated by entertainment and leisure activities in the use of Internet resources. It was revealed that the behavior of girls is predominant, defined as information surfing with a longer stay in the Internet space, boys have a shorter stay («Quickies» and «Single Missions») aimed at solving a specific problem.
\end{abstract}

\section{Introduction}

The development of a digital society has led to changes in all spheres of human life, including this applies to human behavior in the information space.

The use of computer networks leads to significant structural and functional changes in the human mental activity. These changes affect the cognitive, communicative and personal spheres of person.

Actualization of studies on the interaction of man and the information space indicates an increase of interest in this problem and the emergence of different vectors of its study.

Three vectors of research on human behavior in the information space can be distinguished: modern science focuses on information behavior (M. J. Bates, T. D. Wilson, R. S. Taylor, N. J. Belkin, E. V. Kulakova, Yu. N. Dresher, T. A. Atlanova, R. A. Pavlyuk, G. B. Parshukova, M. A. Shchedrin, N. V. Koksin), media behavior (M. V. Zhizhina, I. V. Zhilavskaya, I. V. Zadorin), internet behavior (O.N. Arestova, A.V. Belyaeva, A.E. Voiskunsky). The least represented are studies of Internet behavior.

\footnotetext{
*Corresponding author: galzvezdina@yandex.ru
} 
Behavior is traditionally defined as a certain established way of interacting with the environment, characterized by the ability to change their actions under the influence of internal and external factors. Internet behavior is considered as the behavior of the individual in the Internet environment, in the reality surrounding the individual on the Internet, characterized by non-linearity, artificial creation, globality, unity, continuity. The study of Internet users behavior includes the study of Internet access frequency, output devices, frequency of visits to various Internet resources, topics of interest, duration of the user session, duration of using the page [1].

Usually, information about the Internet behavior of individuals is analyzed through the prism of their socio-demographic characteristics: gender, age, education, income level, and so on. However, recently, more and more attention has been paid to the construction and study of Internet users behavior patterns [2].

\section{Research methods}

Numerous studies show that the main consumers of Internet content are people with higher education and students. In addition, it is obvious that in the student environment there is the greatest variety of goals, motives and forms of Internet behavior: students use the Internet as a source of information for both personal and educational purposes; entering into online communities, students find like-minded people from different parts of the world and get the opportunity to quickly exchange information with them, share the results of their achievements and news; social networks brought social communication in the youth environment to a new level (this applies to communication both with friends and strangers). Moreover, in conditions of excessive involvement in network interaction, a young person often simultaneously experiences both the desire to constantly receive new information content and his own subjectively perceived powerlessness from the inability to control the flow of information. The consequence of this is the formation of an uncritical attitude to information, exposure to manipulative influences, excessive suggestibility, the growing influence of information on human behavior and decisions made, including in the field of morality [3].

All this led us to the need to conduct an empirical study of models of Internet behavior among students of a humanitarian orientation, the results of which will allow us to build a model of psychological security of the person in the Internet environment. For this purpose, the classification of Internet users proposed by Booz-Allen Hamilton and Nielsen // NetRatings Inc [4] was used.

The study involved students, boys and girls aged 18 to 25 , studying at the humanities faculties of universities in Rostov-on-Don and the Rostov Region, in the amount of 60 people, 32 girls and 28 boys.

The classification proposed by Booz-Allen Hamilton and Nielsen/NetRatings Inc is based on such indicators as duration of the user session, number of sites visited, time spent on the site, number of pages to open, time spent on the page (Table 1).

Table 1. Models of Internet behavior: main features

\begin{tabular}{|l|l|l|l|l|}
\hline № & $\begin{array}{l}\text { Model of Internet } \\
\text { behavior }\end{array}$ & $\begin{array}{l}\text { Total session } \\
\text { time }\end{array}$ & Time for 1 site & Type of sites \\
\hline 1 & «Quickies» & $\begin{array}{l}\text { About } \\
\text { minute }\end{array}$ & 15 seconds & $\begin{array}{l}\text { Familiar to the user } \\
(1-2)\end{array}$ \\
\hline 2 & «Just the Facts» & 9 minutes & Not more than 30 & Electronic commerce \\
\hline
\end{tabular}




\begin{tabular}{|l|l|l|l|l|}
\hline 3 & & & sec & sites, online stores \\
\hline 4 & «Do It Again» & 14 minutes & 2 minutes & $\begin{array}{l}\text { Visiting unfamiliar } \\
\text { sites that fall into any } \\
\text { category }\end{array}$ \\
\hline 5 & «Loitering» & 33 minutes & Miscellaneous & $\begin{array}{l}\text { In } 5 \% \text { of cases, time } \\
\text { is spent on sites that } \\
\text { have been visited at } \\
\text { least four times } \\
\text { before }\end{array}$ \\
\hline 6 & «Information Please» & 37 minutes & $\begin{array}{l}\text { The main goal of } \\
\text { accessing the Internet } \\
\text { is leisure, news, } \\
\text { games, entertainment }\end{array}$ \\
\hline 7 & «Surfing» & 70 minutes & About 1 minute & $\begin{array}{l}\text { In-depth study of any } \\
\text { information, the } \\
\text { search is conducted } \\
\text { on many sites that are } \\
\text { already familiar to } \\
\text { the user (about 20) }\end{array}$ \\
$\begin{array}{l}\text { Visit a large number } \\
\text { of sites (about 45). } \\
\text { The study of } \\
\text { information is } \\
\text { extensive, but } \\
\text { superficial, shallow. } \\
\text { Social networks, } \\
\text { online shopping }\end{array}$ \\
\hline
\end{tabular}

As a hypothesis, we suggested that models of Internet behavior among boys and girls may differ.

The research methods were: survey, ranking, frequency analysis, comparative analysis of the results.

The research procedure consisted in ranking the Internet behavior models presented in the classification. It was necessary to build the proposed models in a hierarchy according to the degree of preference.

\section{Main results}

An analysis of various Internet behavior models representation showed that there are some differences between girls and boys (Fig. 1). 


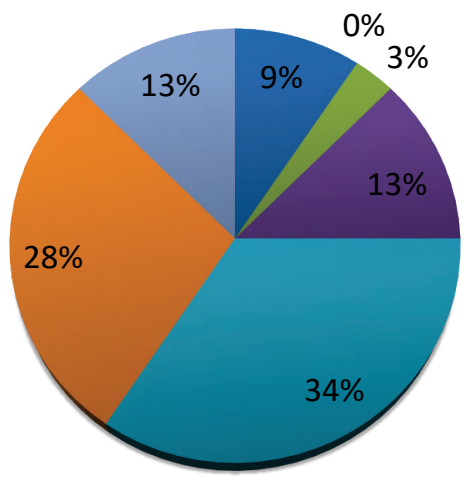

«Quickies»

«Just the Facts»

«Single Missions»

«Do It Again»

«Loitering»

«Information Please»

«Surfing»

Fig. 1. Models of Internet behavior presented in female sample of students

More than a third (34.4\%) of the girls who participated in the study identify themselves as aimless surfers (Model «Loitering»): surfing based on the meaning of the word involves skating or sliding on the surface. A third of young men (30\%) also define their Internet behavior as "aimless surfing"(Model «Loitering»). Internet surfing is the process of viewing pages on web resources. Internet surfing includes visiting social networks, searching for necessary information, reading news and so on. Information rafting can be considered as a way of earning. This type of behavior seems interesting to marketers and advertisers. Reviews from experienced users indicate that Internet surfing is ideal as a side job $[6,7]$.

About a third of respondents $(28.1 \%)$ of girls more often use the model of Internet behavior "Information Please». This behavior model is characterized by a greater involvement of the user in the information, the duration of the sessions lasts more than half an hour - on average 37 minutes. Users visit a fairly wide and familiar arsenal of sites (about 20).

Among male respondents, $22 \%$ of young men use this model of Internet behavior (Fig. 2).

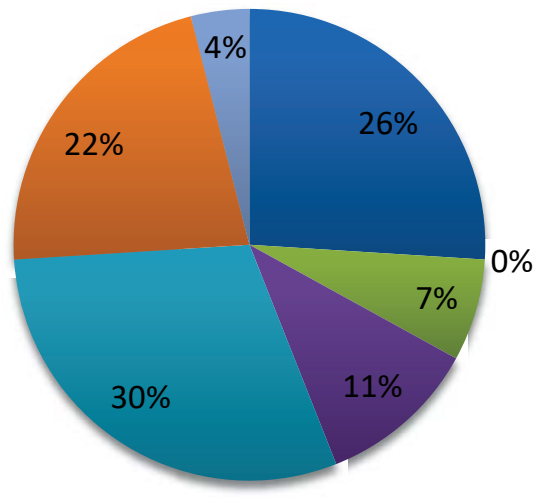

«Quickies»

«Just the Facts»

«Single Missions»

«Do It Again»

«Loitering»

- «Information Please»

— «Surfing» 
Fig. 2 Models of Internet behavior presented in male sample of students

The greatest gender differences are observed in the implementation of the «Quickies» model. Young men use this model of Internet behavior 2.5 times more often than girls. «Quickies» are characterized by fluency in viewing information and a small range of browsed sites.

Young men also more often use the model «Single Missions», which pursues the solution of a specific problem or the search for specific information, the average session lasts 10 minutes, it is typical to visit unfamiliar sites in any category.

Girls use model «Surfing» 4 times more often than boys. Staying in the Internet space takes more than 70 minutes, respondents visit a large number of sites, but the study of information is superficial and shallow.

In the profiles of Internet behavior for both groups of respondents the «Just the Facts» model is not represented: the average session duration is 9 minutes, the time spent on the page does not exceed 30 seconds. As a rule, e-commerce sites and online stores are visited. These indicators can be explained by the fact that the student sample is more focused on the study of entertainment and news information and less on commercial interest.

\section{Discussion of the results}

The analysis of the obtained empirical results allowed us to draw the following conclusions:

- Students of both sexes most often go online to get acquainted with the news, for playing games and entertainment;

- the most popular model of Internet behavior among students of a humanitarian orientation is «Loitering», which is characterized by a relative duration of stay on the site up to 33 minutes;

- The following gender differences were identified in the models of Internet behavior among humanitarian students: male respondents more often use the «Quickies» and «Single missions» models, the time spent on the site is not more than 10 minutes, which may indicate that the advertisement present the site has less impact on them; girls are more likely to use models of informational surfing («Loitering», and «Surfing», «Information please»), which may indicate their longer residence time on sites (up to 70 minutes) and that these respondents are more likely to be under the influence of advertising and various commercial offers;

- A deeper, thoughtful study of information is peculiar to $28 \%$ of girls and $22 \%$ of boys, which suggests that students use Internet resources more often for entertainment and leisure purposes and less for educational purposes.

These research results are the first stage in studying the characteristics of Internet behavior among students. At the next stages it is planned to study the motives and strategies of Internet behavior, and construction of a complex model of individual psychological security in the Internet space.

The article was supported by the Russian Foundation for Fundamental Research (Project No. 18-2922004 (2018) «Psychological and genetic studies of users' behavior predictors that determine the perception of Internet content of various informational orientation»).

\section{References}

1. O.N. Fablinova. Sociological almanac. 6, 543-549 (2015)

2. A. Melnik. Three main patterns of behavior of mobile users (2012) 
3. S.V. Molchanov, O.V. Almazova, N.N. Poskrebisheva, National Psychological Journal. 11(3), 57-68 (2018) doi:10.11621/npj.2018.0306

4. V.M. Foal, O.A. Alekseeva, O.N. Vershinskaya, Population. 1, 118-123 (2017)

5. Y.N. Drescher, T.A. Atlanova, The study of information needs and information behavior of specialists in the structure of activities to ensure a comfortable information environment (2005) 